\title{
The Lactococcus genus as a potential emerging mastitis pathogen group: A report on an outbreak investigation
}

\author{
M. X. Rodrigues, ${ }^{*}$ S. F. Lima, $†$ C. H. Higgins, $†$ S. G. Canniatti-Brazaca, ${ }^{*}$ and R. C. Bicalho ${ }^{1}$ \\ *Department of Agroindustry, Food and Nutrition, Luiz de Queiroz College of Agriculture, University of São Paulo, Piracicaba, SP13418-900, Brazil \\ †Department of Population Medicine and Diagnostic Sciences, College of Veterinary Medicine, Cornell University, Ithaca, NY 14853
}

\begin{abstract}
The bacterium Lactococcus lactis is widely used in food production and in medical applications, and is considered safe for human and animal use. However, studies have also linked Lactococcus bacteria to infection. For example, certain variants of Lactococcus species have been associated with bovine mastitis (e.g., Lactococcus lactis and Lactococcus garvieae). In this study, we investigated an outbreak of bovine mastitis thought to be associated with Lactococcus bacteria by using microbiological and molecular techniques. We used bacterial isolation, next-generation sequencing, DNA fingerprinting, and other methods to test our hypothesis that Lactococcus microbes were the primary pathogen causing the mastitis outbreak. Twenty-eight Lactococcus isolates were obtained from mastitic milk of 28 dairy cows. The isolates were identified as L. lactis (27 isolates) and L. garvieae (1 isolate). Phylogenetic analysis based on $16 \mathrm{~S}$ rDNA gene sequence comparison indicated similarity among the L. lactis isolates as well as between the isolates and reference sequences. The DNA fingerprinting analysis based on random amplified polymorphic DNA results of the 27 L. lactis isolates identified different random amplified polymorphic DNA profiles, which suggests they originated from multiple sources. Microbiome analysis determined Lactococcus to be the dominant genus in the majority of the mastitic milk samples, whereas it was found in low relative abundance in healthy milk samples. The Lactococcus genus was detected in all environmental samples tested, and sampling of bulk tank milk corroborated that Lactococcus was not abundant in healthy milk from the same dairy herd. In summary, our findings suggest that Lactococcus bacteria are a potential etiological agent in the mastitis outbreak studied. Further studies should be conducted to understand the importance of Lacto-
\end{abstract}

Received March 7, 2016.

Accepted August 9, 2016

${ }^{1}$ Corresponding author: rcb28@cornell.edu coccus, especially L. lactis, as pathogenic microbes in veterinary medicine and food safety.

Key words: mastitis, Lactococcus, microbiome, next generation sequencing

\section{INTRODUCTION}

Mastitis is an important disease in dairy cows causing reproduction problems (Hertl et al., 2010), culling (Gröhn et al., 2005), and economic losses due to reduced milk production, treatment expense, and discarded milk (Bar et al., 2008). Clinical mastitis is also a painful disease and is associated with behavioral changes (Medrano-Galarza et al., 2012).

For treatment of mastitis, identifying the microorganisms responsible should be considered (Royster and Wagner, 2015). Many microbial species have been identified as etiological agents, typically through bacterial culture (Oikonomou et al., 2012). Lactococcus species have been isolated from bovine mastitis, and their association with the disease has been discussed (Werner et al., 2014; Plumed-Ferrer et al., 2015a). Lactococci are gram-positive, nonmotile cocci, homofermentative, poorly $\alpha$-hemolytic, and exclusively produce $\mathrm{L}(+)$ lactic acid (Casalta and Montel, 2008). They are members of the group lactic acid bacteria (LAB) and are routinely found on animal skin and plants (Casalta and Montel, 2008). Lactic acid bacteria are generally not considered harmful to humans (Mofredj et al., 2007) or animals (Klostermann et al., 2008; Espeche et al., 2012; Bouchard et al., 2015) and have been used for the prevention and treatment of human (Mofredj et al., 2007) and animal diseases (Klostermann et al., 2008; Espeche et al., 2012; Bouchard et al., 2015). Lactic acid bacteria have been reported to produce proteins, chemical mediators, and other molecules that stimulate local immune responses (Mofredj et al., 2007).

Interestingly, in dairy cows, the potential of LAB for treatment or prevention (or both) of mastitis has been considered (Klostermann et al., 2008; Espeche et al., 2012; Bouchard et al., 2015). Klostermann et al. (2008) evaluated the use of a live culture suspension of 
Lactococcus lactis DPC3147 to treat naturally infected mastitic animals. Trials were conducted for subclinical and acute clinical mastitis, which demonstrated that treatment with L. lactis DPC3147 culture potentially had a similar level of efficacy as common antibiotics (Klostermann et al., 2008).

Lactococcus lactis, in particular, is of considerable economic importance (Cavanagh et al., 2015) and is widely used as a starter culture in dairy fermentation (Casalta and Montel, 2008). Lactococcus lactis is known to produce bacteriocin (Klostermann et al., 2008) and is frequently used as a probiotic (Furtado et al., 2014). Moreover, L. lactis is included on the Qualified Presumption of Safety list of the European Food Safety Authority (Plumed-Ferrer et al., 2013) and is accepted as generally recognized as safe (Casalta and Montel, 2008). However, some species of Lactococcus have been reported to be the cause of human (Davies et al., 2009; Hadjisymeou et al., 2013; Inoue et al., 2014) and animal infections (Plumed-Ferrer et al., 2013, 2015a; Khoo et al., 2014). Nevertheless, it is unclear if these cases represent the emergence of novel pathogenic strains or were detected due to the availability of improved identification methods (Plumed-Ferrer et al., 2015b).

Werner et al. (2014) confirmed, by using a DNA sequencing approach, that the majority of isolates from bovine mastitis milk samples, which were phenotypically identified as Streptococcus spp., were in fact L. lactis. Lactococcus species are closely related to streptococci and Streptococcus-like genera such as Enterococccus and Aerococcus. Therefore, the role of Lactococcus spp. as an etiological agent of mastitis may have been underreported throughout the years (Werner et al., 2014). Considering this, Lactococcus species isolated from bovine intramammary infections are now being characterized both genotypically and phenotypically (Plumed-Ferrer et al., 2013, 2015a; Werner et al., 2014). However, the mechanism of pathogenicity is not yet fully understood (Plumed-Ferrer et al., 2015b), and few studies have been conducted on lactococci as potential bovine mastitis pathogens.

Therefore, the aim of the present study was to use current microbiological and molecular techniques to investigate an outbreak of mastitis that was thought to be associated with Lactococcus infection. Specifically, we hypothesized that a member(s) of the Lactococcus genus was the primary pathogen causing the mastitis outbreak. To explore our hypothesis, we used nextgeneration sequencing of the $16 \mathrm{~S}$ rRNA gene, random amplified polymorphic DNA-PCR (RAPD-PCR), and phylogenetic techniques.

\section{MATERIALS AND METHODS}

\section{Animal Care Statement}

All experimental procedures in this study conformed to the recommendations of The Animal Welfare Act of 1966 (P.L. 89-544) and its amendments of 1970 (P.L. 91-579), 1976 (P.L. 94-279), and 1985 (P.L. 99-1998), which regulate the transportation, purchase, and treatment of animals used in research. The research protocol was reviewed and approved by the Institutional Animal Care and Use Committee of Cornell University (protocol number: 2013-0056).

\section{Farm and Management}

The study was conducted on a single commercial dairy farm located in upstate New York. During the experimental period, from July until October 2015, the farm milked approximately 1,200 cows. Primiparous and multiparous cows were housed separately in freestall barns bedded with sand. Cows were fed a TMR to meet or exceed the nutrient requirements of a $650-\mathrm{kg}$ lactating Holstein cow producing $45 \mathrm{~kg} / \mathrm{d}$ of milk with $3.5 \%$ fat and $3.2 \%$ true protein when DMI is $25 \mathrm{~kg} / \mathrm{d}$ (NRC, 2001). Cows were milked thrice daily in a double-20 milking parlor.

The target length of the dry period was $55 \mathrm{~d}$. Cows were dried off by abrupt interruption of milking and dry cow therapy was equally performed for all quarters of all cows and consisted of intramammary infusion with ceftiofur hydrochloride (Spectramast DC, Zoetis, Madison, NJ) followed by the administration of an internal teat sealant (Orbeseal, Zoetis). Before the outbreak of Lactococcus spp., the common mastitis pathogens encountered based on aerobic mastitic milk culture were represented by approximately $33 \%$ gramnegative microbes, mainly Escherichia coli and Klebsiella; $33 \%$ gram-positive microbes, mainly Streptococcus uberis, Streptococcus dysgalactiae, Streptococcus spp., and Staphylococcus spp.; and 33\% were culture negative from a total of approximately 500 mastitic milk samples evaluated during a period of $1 \mathrm{yr}$ prior to the Lactococcus outbreak. The historical clinical cure rates following intramammary antibiotic therapy of clinical mastitis were approximately $70 \%$. The bulk tank SCC ranged from 150,000 to 250,000 . The herd is a closed herd with no other major concomitant disease problems. The incidence of displaced abomasum, ketosis, metritis, and retained placenta were $2.5,5,12$, and $6 \%$, respectively. 


\section{Enrollment Criteria, On-Farm Culture, and Sample Collection}

Clinical mastitis was identified by the presence of abnormal milk, such as a watery appearance, flakes, and clots; the identification was performed thrice daily in the milking parlor by farm employees. On a daily basis, milk samples from all clinical mastitis cases (from mild to severe cases of mastitis) were cultured using the AccuMast-Mastitis Culture System (FERA Animal Health, Dryden, NY). The AccuMast system consists of a single Petri dish with 3 selective chromogenic media used to identify and differentiate specific mastitis pathogens (Ganda et al., 2016). Ganda et al. (2016) validated the on-farm use of AccuMast by comparing its results with the results of a referral laboratory and also to $16 \mathrm{~S}$ rRNA gene sequencing. Unfortunately, no Lactococcus mastitis cases were identified in that study. The present study was motivated by the fact that the farm manager of the study farm noticed the appearance of a unique coloration pattern for an increasing number of cows cultured using the AccuMast system (Figure 1). Plates were incubated aerobically at $37^{\circ} \mathrm{C}$ for a period of 16 to $20 \mathrm{~h}$ when interpretation of test results was performed by a trained farm employee, and affected cows that had culture results consistent with suspected infection by a Lactococcus species (Figure 1D) were eligible to enter the study. Before intramammary antibiotic treatment was started and within $24 \mathrm{~h}$ of the initial diagnosis, a fresh milk sample was aseptically collected from cows that were considered Lactococcus positive by a trained farm employee, a total of 28 samples from 28 different cows. Briefly, the teat ends were cleaned, disinfected, and the first streams were discarded before a sample of
A)
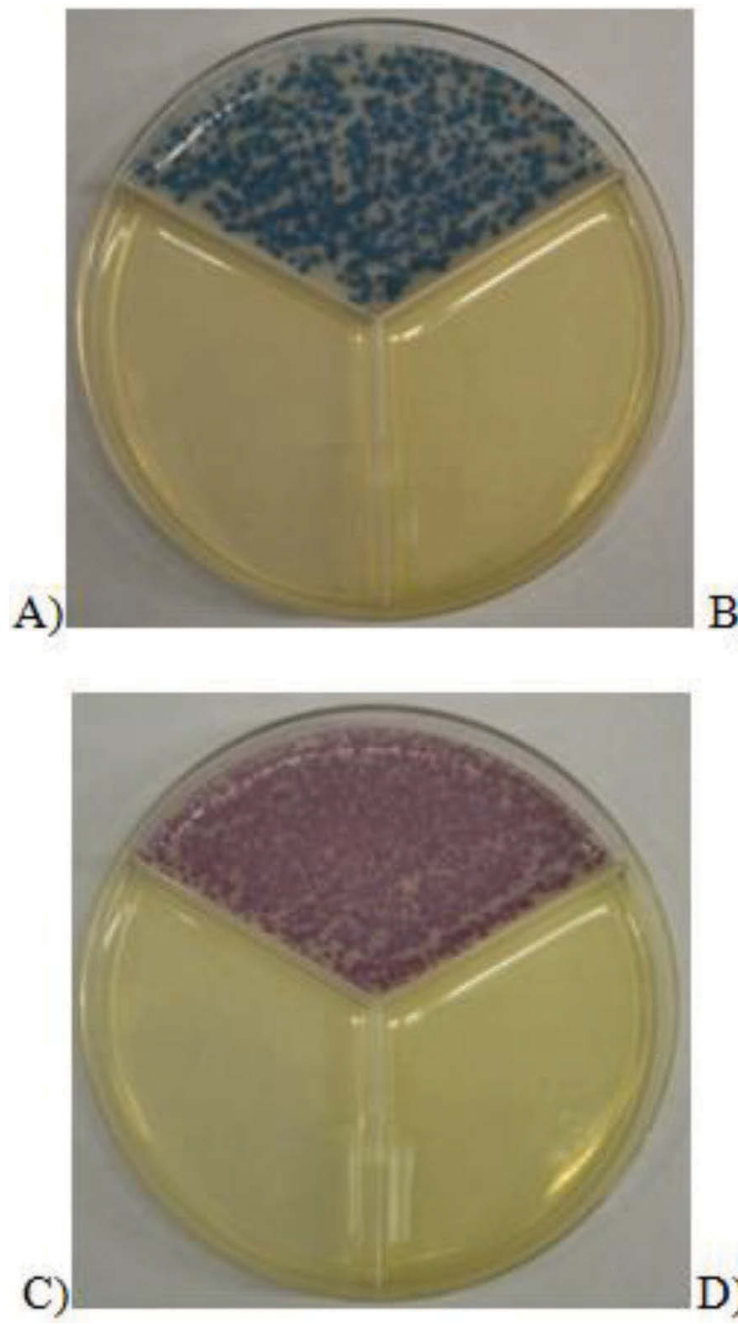

B)
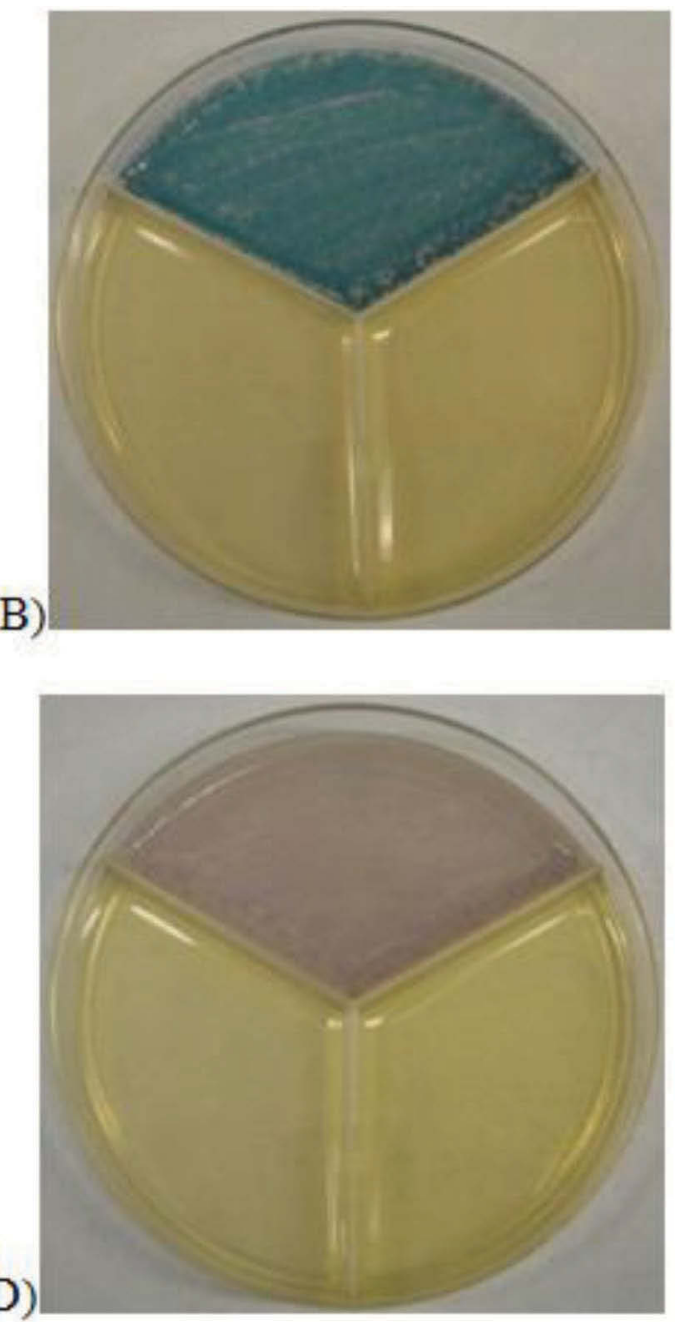

Figure 1. Growth characteristics of different bacteria on the second section of the AccuMast-Mastitis Culture System (FERA Animal Health, Dryden, NY). Growth of (A) Streptococcus uberis (ATCC 700407); (B) Streptococcus agalactiae (ATCC 27956); (C) Enterococcus faecalis (ATCC 29212); and (D) Lactococcus lactis isolated from mastitic milk in this study. Color version available online. 
approximately $8 \mathrm{~mL}$ of milk was collected in a sterile vial from each clinically diseased quarter. Additionally, quarter milk samples from 30 clinically healthy cows were collected to serve as a baseline comparison for the microbiome studies. All samples were kept refrigerated, (for approximately $2 \mathrm{~h}$ ) while being transported to our laboratories at Cornell University for further processing.

To investigate the potential environmental sources of Lactococcus spp., we collected random sand bedding samples from different cow pens: 5 samples from the superficial layer and 5 samples from the deep layer for microbiome investigation. A bulk tank milk sample was also collected for microbiome investigation, transported on ice to the laboratory, and then stored at $-20^{\circ} \mathrm{C}$ until further processing. All samples were collected as soon as the outbreak was identified by farm employees.

\section{Bacterial Isolation and Bacterial Identification by the Sanger Sequencing Method}

Mastitic milk samples considered Lactococcus spp. positive were aseptically inoculated onto CHROMagar StrepB (CHROMagar, Paris, France) using sterile swabs, and incubated under aerobic conditions at $37^{\circ} \mathrm{C}$ for up to $24 \mathrm{~h}$. Single, light pink colonies from each sample were selected and streaked onto the same chromogenic culture medium and incubated under the same conditions. Good bacterial growth was observed after the first inoculation; thus, this step was repeated 3 times to generate a pure culture from each mastitic milk sample. Next, the bacterial colonies were inoculated into Bacto Brain Heart Infusion broth (Becton, Dickinson and Company, Sparks, MD) and incubated overnight at $37^{\circ} \mathrm{C}$; these cultures were used to prepare stocks (bacterial cultures stored in 50\% glycerol at $-20^{\circ} \mathrm{C}$ for further use) and to extract DNA.

The DNA was extracted from each bacterial isolate using InstaGene Matrix (Bio-Rad Laboratories Inc., Hercules, CA) following the manufacturer's instructions. The extracted DNA was quantified using a NanoDrop ND-1000 spectrophotometer (NanoDrop Technologies, Rockland, DE). The 16S ribosomal DNA gene was amplified using $10 \mathrm{pmol}$ of each fD1forward and $\mathrm{rP} 2$ reverse primers (Weisburg et al., 1991), EconoTaq Plus Green 1× Master Mix (Lucigen, Middleton, WI), 280 to $350 \mathrm{ng}$ of template DNA, and ultrapure distilled water to bring the final reaction volume to 100 $\mu \mathrm{L}$. The conditions for amplification were $94^{\circ} \mathrm{C}$ for 5 $\min , 57^{\circ} \mathrm{C}$ for $2 \mathrm{~min}$, and $72^{\circ} \mathrm{C}$ for 2 min followed by 29 cycles of $94^{\circ} \mathrm{C}$ for $2 \mathrm{~min}, 57^{\circ} \mathrm{C}$ for $30 \mathrm{~s}$, and $72^{\circ} \mathrm{C}$ for 2 min, with a final extension of $72^{\circ} \mathrm{C}$ for $10 \mathrm{~min}$ (Wood et al., 1998). Agarose gel electrophoresis (1.2\% wt/vol) was used to verify the presence of PCR products. The DNA was visualized with $0.5 \mu \mathrm{g} / \mathrm{mL}$ ethidium bromide.

The PCR products were purified using a Gel/PCR Fragments Extraction Kit (IBI Scientific, Peosta, IA) in accordance with the manufacturer's recommendations. The purified samples were submitted to the Cornell University Life Science Core Laboratories Center for Sanger sequencing using $8 \mathrm{pmol}$ of primer fD1 and 300 ng of PCR products. FASTA sequences were compared against sequences stored in GenBank using the BLAST algorithm (http://blast.ncbi.nlm.nih.gov/Blast.cgi; Benson et al., 2009; Sayers et al., 2009).

\section{Phylogenetic Analysis}

Using Geneious software version 9.0.4 (Biomatters, Auckland, New Zealand), the 16S rDNA sequences (Sanger sequencing), amplified from all individual bacterial isolates, were aligned with each other and with relevant reference sequences obtained from the Ribosomal Database Project (Cole et al., 2014): Lactococcus garvieae (JCM8735; AB012306), L. lactis (MRS1; AJ488173), L. lactis ssp. cremoris (CF4; AB181302), L. lactis ssp. lactis (MR26, AF493057), Lactococcus piscium (fish isolate HR1A-68.; X53905), Lactococcus raffinolactis (NCDO617; X54261), Streptococcus agalactiae [(T); JCM 5671; AB023574], Streptococcus dysgalactiae (ATCC 35666; AJ319643), and S. uberis [(T); JCM 5709; AB023573]. Sequences were aligned using the Clustal W method (Larkin et al., 2007) and the final alignment was corrected manually. Evolutionary distances were computed using the Tamura-Nei method (Tamura and Nei, 1993) and the phylogenetic tree was constructed by applying the neighbor-joining method (Saitou and Nei, 1987).

\section{RAPD-PCR}

The RAPD-PCR was performed as previously described by Akopyanz et al. (1992) using primer 1254 . The reactions were performed using 10 pmol of 1254 primer, $1 \times$ EconoTaq Plus Green Master Mix (Lucigen), 280 to $350 \mathrm{ng}$ of template DNA, and ultrapure distilled water was used to bring the final reaction volume to $50 \mu \mathrm{L}$. The cycling program was 4 cycles of $94^{\circ} \mathrm{C}$ for $5 \mathrm{~min}, 36^{\circ} \mathrm{C}$ for $5 \mathrm{~min}$, and $72^{\circ} \mathrm{C}$ for $5 \mathrm{~min}$, followed by 30 cycles of $94^{\circ} \mathrm{C}$ for $1 \mathrm{~min}, 36^{\circ} \mathrm{C}$ for $1 \mathrm{~min}$, and $72^{\circ} \mathrm{C}$ for $2 \mathrm{~min}$, and then a final extension at $72^{\circ} \mathrm{C}$ for $10 \mathrm{~min}$ (Akopyanz et al., 1992). The products of the reaction were visualized by electrophoresis using a $2 \%$ (wt/vol) agarose gel with $0.5 \mu \mathrm{g} / \mathrm{mL}$ ethidium bromide. The profiles were compared visually and clustered according to suggested similarity. 


\section{Metagenomic DNA Extraction and Next-Generation Sequencing of the Bacterial 16S rRNA gene}

Samples of mastitic milk, milk from healthy cows, bulk tank milk, and sand bedding were analyzed by metagenomic sequencing of the $16 \mathrm{~S}$ rRNA gene using the Illumina MiSeq platform (Illumina Inc., San Diego, CA). The DNA was extracted from all samples by using a PowerSoil DNA Isolation Kit (MO BIO Laboratory Inc., Carlsbad, CA) following the manufacturer's instructions. The $515 \mathrm{f}-806 \mathrm{rB}$ region of the $16 \mathrm{~S} \mathrm{rRNA}$ gene was amplified according to a previous study (Caporaso et al., 2010). Barcoded primers were used as previously described by Lima et al. (2015).

Amplification of the V4 hypervariable region of the $16 \mathrm{~S}$ rRNA gene was completed using $10 \mathrm{pmol}$ of each primer, EconoTaq Plus Green 1× Master Mix (Lucigen), 10 to $50 \mathrm{ng}$ of template DNA, and ultrapure water to bring the final reaction volume to $25 \mu \mathrm{L}$. All reactions were set up in triplicate, and the PCR cycles were $94^{\circ} \mathrm{C}$ for $3 \mathrm{~min}, 35$ cycles of $94^{\circ} \mathrm{C}$ for $45 \mathrm{~s}, 50^{\circ} \mathrm{C}$ for $1 \mathrm{~min}, 72^{\circ} \mathrm{C}$ for $90 \mathrm{~s}$, and $72^{\circ} \mathrm{C}$ for $10 \mathrm{~min}$. Replicates were pooled, visualized by electrophoresis through $1.2 \%$ (wt/vol) agarose gels stained with $0.5 \mathrm{mg} / \mathrm{mL}$ ethidium bromide and purified using a Gel/PCR Fragments Extraction Kit (IBI Scientific). The amplicons were quantified using a Qubit 2.0 Fluorometer (Invitrogen by Life Technologies, Carlsbad, CA), standardized to the same concentration and pooled for sequencing on the Illumina MiSeq platform. A final equimolar library was sequenced using the MiSeq Reagent Nano Kit V2 (300 cycles, Illumina Inc.).

\section{Analysis of Results}

The results from Sanger sequencing, RAPD-PCR, and MiSeq Reporter Metagenomics Workflow for relative abundance and taxonomy, with a focus on genera, were descriptive. To illustrate the relative abundances of the 30 most abundant bacterial genera in the different samples evaluated, we generated a heatmap using JMP software (version 11, SAS Institute Inc., Cary, NC). Analysis of variance, implemented in JMP, was used to compare the relative abundances of Lactococcus between milk from mastitic and healthy cows.

\section{RESULTS}

Initial screening using the AccuMast-Mastitis Culture System identified 28 mastitic milk samples with colonies characteristic of Lactococcus spp. The typical colonies of Lactococcus are shown in Figure 1D. The samples were inoculated onto CHROMagar to identify and confirm the presence of a typical lactococcal colony.
In all samples, typical colonies were obtained and the isolates were identified by Sanger sequencing of the $16 \mathrm{~S}$ rDNA gene as L. lactis (27 isolates) and L. garvieae (1 isolate).

Alignment of each of the $16 \mathrm{~S}$ rDNA gene sequences of the $27 \mathrm{~L}$. lactis isolates and an L. lactis reference (MRS1; AJ488173) strain revealed a pairwise identity of $99.8 \%$. The single L. garvieae isolate had a pairwise identity of $98.9 \%$ with the L. garvieae reference sequence (JCM8735; AB012306). High similarity among the isolates was evident from the phylogenetic tree generated using the $16 \mathrm{~S}$ rDNA gene sequences (Figure 2). Furthermore, we observed higher similarity between the isolates and the L. lactis ssp. cremoris (CF4; AB181302) compared with the L. lactis ssp. lactis (MR26, AF493057).

We DNA fingerprinted the 27 L. lactis strains using the RAPD technique, which all showed a good RAPD banding pattern using primer 1254. Visual analysis suggested different RAPD profiles (Figure 3). Whereas several distinct RAPD profiles were observed, some isolates had a similar pattern (Figure 3).

Quality-filtered reads for the $16 \mathrm{~S}$ rRNA gene sequences were demultiplexed, yielding 4,899,000 sequences in total with a median length of 301 bases per read and an average coverage of 71,000 $(\mathrm{SEM}=2,150)$ sequences per sample. We found 634 genera in mastitic milk samples and the 17 most abundant are shown in Figure 4. Lactococcus was detected in all samples, with 1.95 to $96.6 \%$ relative abundance, being the dominant genus in the majority of samples. A higher relative abundance of the Lactococcus genus was evident in the microbiome of mastitic milk samples compared with the microbiome of healthy milk samples (Figure 5). The average relative abundance of the genus Lactococcus for healthy milk was below $0.1 \%$, which was 20 times lower than the relative abundance of Lactococcus in the mastitic milk. In sand bedding and bulk tank milk samples, 690 genera were identified, and the 30 most abundant are shown in Figure 6. Lactococcus was present in all samples. Interestingly, Bergeyella and Acinetobacter were the most abundant in the sand bedding samples, and Chryseobacterium and Enhydrobacter in the bulk tank sample. Accordingly, as in the healthy milk samples, we observed a low relative abundance of the Lactococcus genus in the bulk tank milk sample, specifically $0.5 \%$ (Figure 6).

\section{DISCUSSION}

Our investigation of an outbreak of bovine mastitis on a dairy farm showed that species within the Lactococcus genus are a potential cause of the disease. It is possible that Lactococcus strains already existed in 
the study herd before the investigated outbreak given the possibility that the referral laboratory misclassified the cases as Streptococcus spp. (Werner et al., 2014). However, the outbreak may have been the consequence of the introduction of new Lactococcus strains or changes in the environment that selectively favored the pre-existing Lactococcus strains. Lactococcus lactis was the dominant species detected and $L$. garvieae was the only other Lactococcus species identified. Phylogenetic tree analysis, using the $16 \mathrm{~S}$ rRNA gene, confirmed that all isolates were clustered with reference L. lactis sequences and only one isolate clustered with a known L. garvieae sequence. Microbiome analysis determined the Lactococcus genus to be dominant in most mastitic samples, with a high relative abundance, and Lactococcus genus was also identified in all investigated environmental samples. Conversely, Lactococcus bacteria were found at only low relative abundance in healthy milk and in bulk tank milk. These data support our hypothesis that bacteria of the genus Lactococcus were

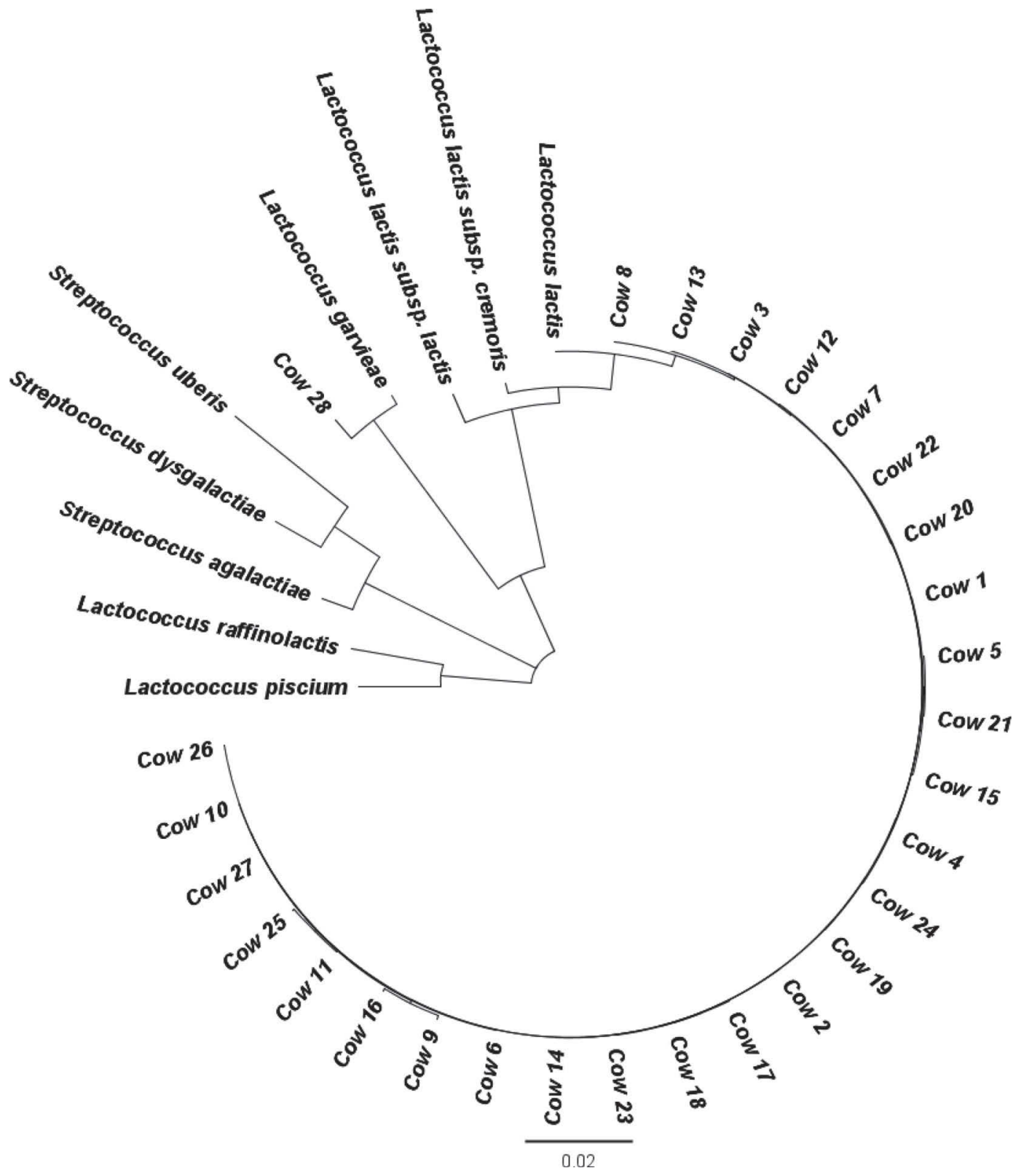

Figure 2. Phylogenetic tree based on the sequences of 28 isolates from mastitic milk samples (where each cow is represented by an isolate) and the reference sequences used: Lactococcus garvieae (JCM8735; AB012306), Lactococcus lactis (MRS1; AJ488173), L. lactis ssp. cremoris (CF4; AB181302), L. lactis ssp. lactis (MR26, AF493057), Lactococcus piscium (fish isolate HR1A-68.; X53905), Lactococcus raffinolactis (NCDO617; X54261), Streptococcus agalactiae [(T); JCM 5671; AB023574], Streptococcus dysgalactiae (ATCC 35666; AJ319643), and Streptococcus uberis [(T); JCM 5709; AB023573]. 
the primary pathogen causing the mastitis outbreak. We used molecular techniques (e.g., next-generation sequencing) with increased accuracy and reliability to support our conclusions.

Methods based on PCR have greater accuracy than traditional methods for the identification of species (Kuang et al., 2009; Plumed-Ferrer et al., 2013). Therefore, we used Sanger sequencing, which identified L. lactis and L. garvieae in mastitic milk samples, consistent with other recent studies (Plumed-Ferrer et al., 2013, 2015a; Werner et al., 2014). The questionable reliability of traditional methods for identifying common and emerging mastitis pathogens is a concern. Phenotypic and biochemical methods for identification of streptococci and streptococci-like bacteria are thought to be inaccurate and inconsistent (Fortin et al., 2003; Werner et al., 2014). For example, Werner et al. (2014) found that traditional methods overestimated the abundance of $S$. uberis and failed to identify $L$. lactis ssp. lactis. Similarly, Plumed-Ferrer et al. (2013) concluded that phenotypic tests have likely underestimated the incidence of Lactococcus in clinical samples throughout the years. Furthermore, in another study, the API 20 Strep System misidentified Lactococcus isolates as Enterococcus faecium and Enterococcus spp.; their true identities were subsequently determined by 16S rRNA gene sequencing to be L. lactis ssp. lactis and L. garvieae (Wyder et al., 2011).

Phylogenetic analysis using the 16s rRNA gene revealed that the majority of the Lactococcus isolates were closely clustered with the L. lactis ssp. cremoris strain (CF4; AB181302). In humans, infections caused by Lactococcus, specifically L. lactis ssp. cremoris, are generally rare (Hadjisymeou et al., 2013); however, during the past $50 \mathrm{yr}$ numerous case reports of infection have been published (Davies et al., 2009). Many of these cases were associated with unpasteurized dairy products or immunodeficiency, and in one case the bacterium was isolated from a dairy product (Hadjisymeou et al., 2013; Inoue et al., 2014). Lactococcus bacteria remain viable in transit through the gastrointestinal tract, which is believed to be the mode of infection in humans (Hadjisymeou et al., 2013). The pathogenicity of L. lactis ssp. cremoris is unknown and its route of infection is not well understood (Inoue et al., 2014). Both L. lactis ssp. cremoris and L. garvieae have been isolated from bovine mastitis (Plumed-Ferrer et al., 2013, 2015b). Lactococcus garvieae is a known important pathogen in aquaculture, and some human cases of $L$. garvieae infection had a history of patient contact with raw fish (Navas et al., 2013).

All of the isolates we identified as L. lactis from different animals were DNA-fingerprinted by RAPDPCR. Several different RAPD profiles were present and a few patterns seemed to occur in multiple cows, which could indicate point source infection, contagious transmission, or lack of discriminatory power, as previously explored for other mastitis pathogens (Daly et al., 1999; Munoz et al., 2007). Herein, we should consider the possibility that different cows were being infected by a common source, which could explain the fact that some Lactococcus isolates had similar RAPD-PCR agarose gel profiles. Only a few studies have used RAPD-PCR for DNA fingerprinting of Lactococcus isolates (Tailliez et al., 1998; Mangin et al., 1999; Plumed-Ferrer et al., 2015a), and further studies are still needed to validate this technique for differentiation of Lactococcus isolates. Additional studies are warranted to elucidate the mode of transmission of Lactococcus and also to evaluate the short and long-term effect of Lactococcus mastitis on cow health, milk production, quality, and composition.

We assessed the microbial diversity in mastitic milk, sand bedding, and bulk tank milk. The $16 \mathrm{~S}$ rRNA gene sequencing of microbes in mastitic milk identi-

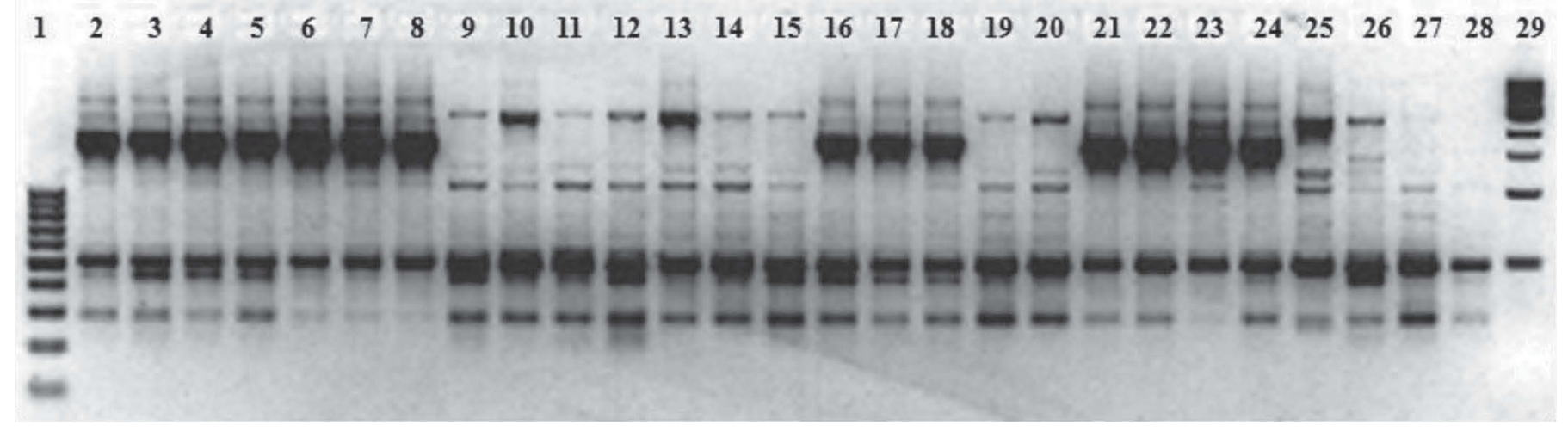

Figure 3. Random amplified polymorphic DNA-PCR analysis using primer 1254 to fingerprint 27 Lactococcus lactis strains isolated from mastitic milk. Lane $1=100$-bp DNA ladder (Omega Bio-Tek, Norcross, GA), lanes 2 to 28 = isolates from cows 3, 17, 20, 4, 21, 5, 2, 23, 9, 7, 25, $15,19,14,22,24,1,8,12,18,16,6,10,26,13,27$, and 11, respectively; and lane $29=1$-kb ladder (New England BioLabs Inc., Ipswich, MA). 


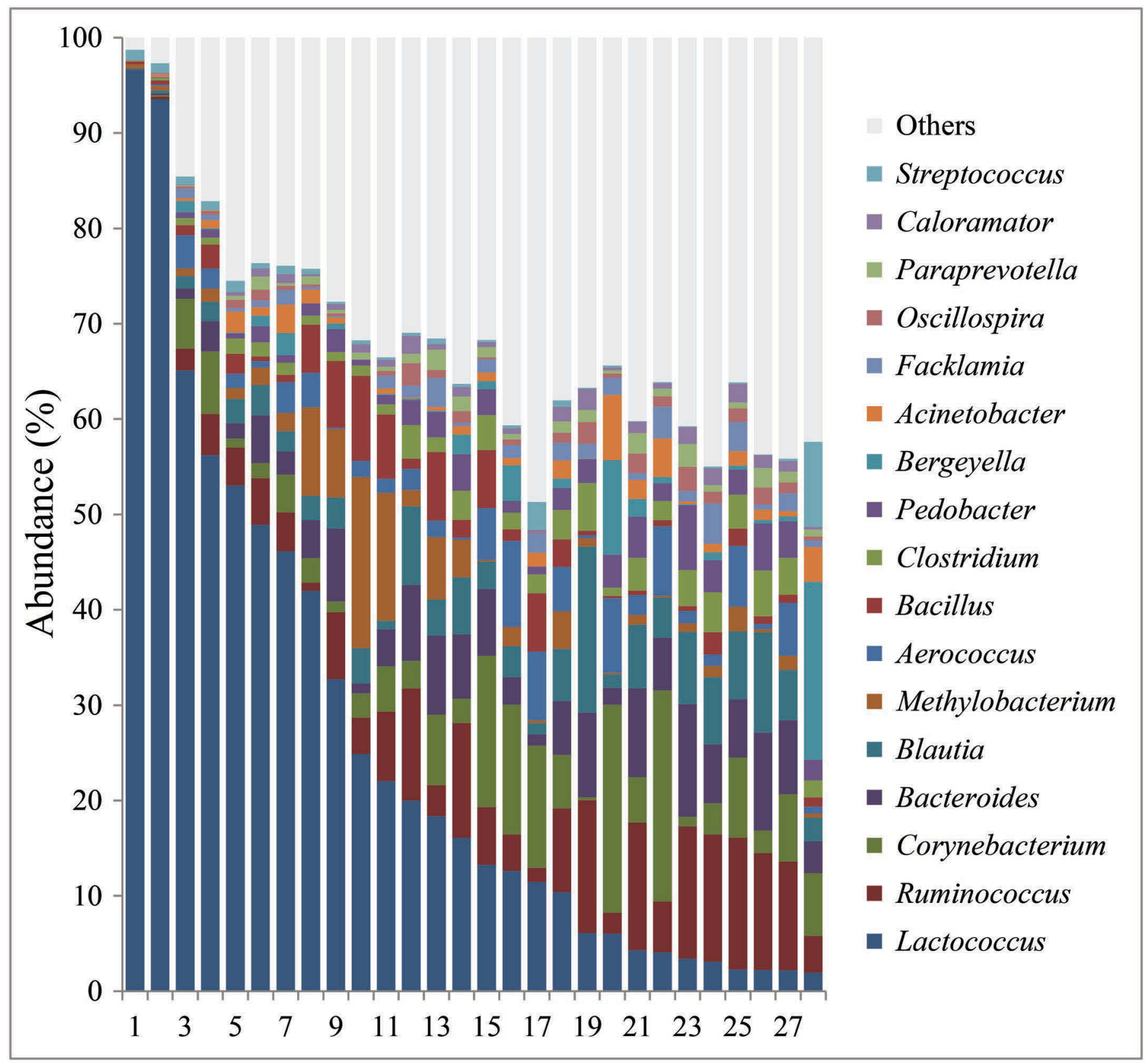

Figure 4. Mean relative abundance of the 17 most prevalent bacterial genera identified in mastitic milk samples (others $=$ sum of all other genera). Color version available online.

fied Lactococcus in all samples; in fact, it was the most abundant genus in the majority of samples (Figure 4). Whereas previous studies using 16S rRNA gene sequencing did not identify this genus as being among the most abundant in milk samples (Oikonomou et al., 2012, 2014), other studies using culture-independent methods showed that Lactococcus was widely distributed in raw milk, pasteurized milk (Quigley et al., 2013), and raw milk from bovine mastitis (Kuang et al., 2009). Therefore, we compared the relative abundance of the Lactococcus genus in mastitic and nonmastitic milk samples (Figure 5). The results showed a higher relative abundance of Lactococcus in mastitic milk, suggesting that species within this genus are potential etiologic agents of disease.

Microbial diversity analysis of sand bedding and bulk tank milk identified Lactococcus in all samples; it was present among the 30 most prevalent bacterial genera (Figure 6). In bulk tank milk, Lactococcus was not highly abundant, which confirms that Lactococcus was 
not common in milk of healthy cows in the study herd. In addition, Chryseobacterium and Enhydrobacter were the most prevalent genera in bulk tank milk. Chryseobacterium spp. are psychrotrophic bacteria frequently detected in dairy products (Delbès et al., 2007; MunschAlatossava et al., 2012). Enhydrobacter is a rare genus with only a single species, Enhydrobacter aerosaccus (Kawamura et al., 2012), and has been identified in dairy products at a low level (Oki et al., 2014). It was not expected to be abundant within the milk samples; however, little information has been published regarding this genus. Further studies on Enhydrobacter are necessary to assess its importance in the dairy industry.

In sand bedding samples, Lactococcus was detected in all samples, which could indicate that sand bedding was a potential reservoir for Lactococcus. However, it is also possible that the sand bedding evaluated herein was not the primary source of contamination but was simply contaminated by milk leakage from infected cows while they were lying down; samples analyzed in the present study were collected directly from the freestalls. Nevertheless, the identification of Lactococcus in the sand bedding indicates that this microbe could be transmitted from cow to cow via the contaminated sand or the sand bedding could be a direct primary source of contamination.

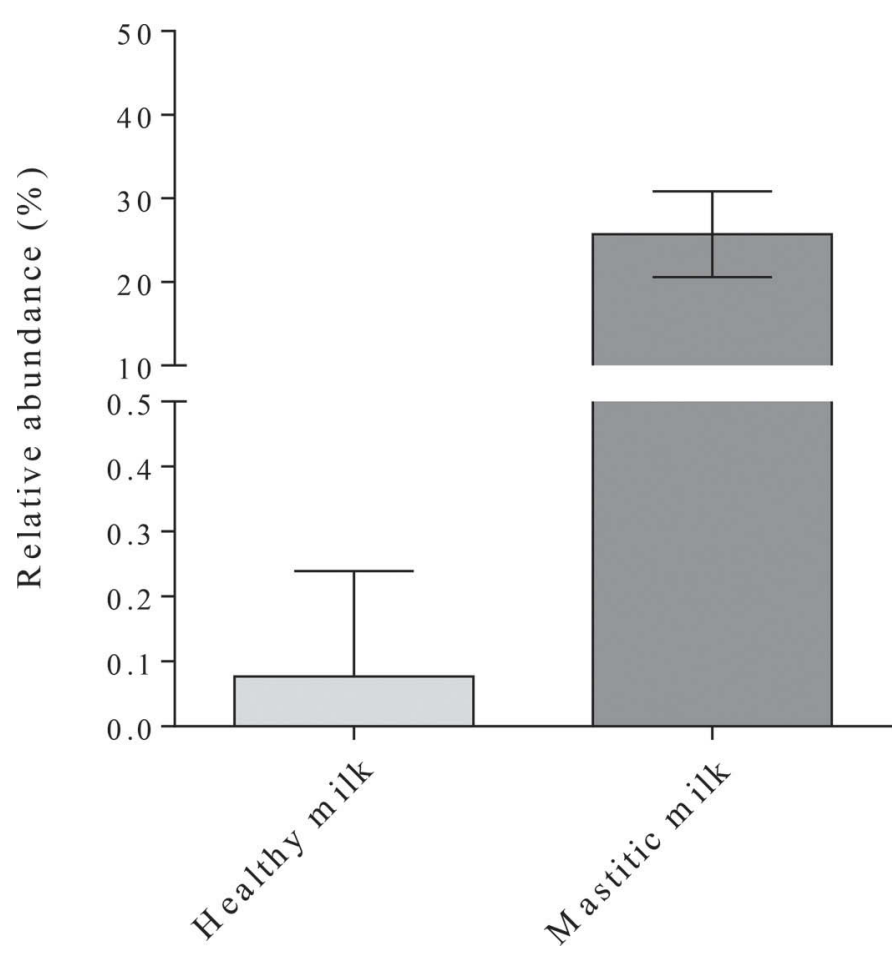

Figure 5. Mean of relative abundance of Lactococcus in healthy milk $(\mathrm{n}=30)$ versus mastitic milk $(\mathrm{n}=28)$. Error bars represent the standard deviation of the mean relative abundance.
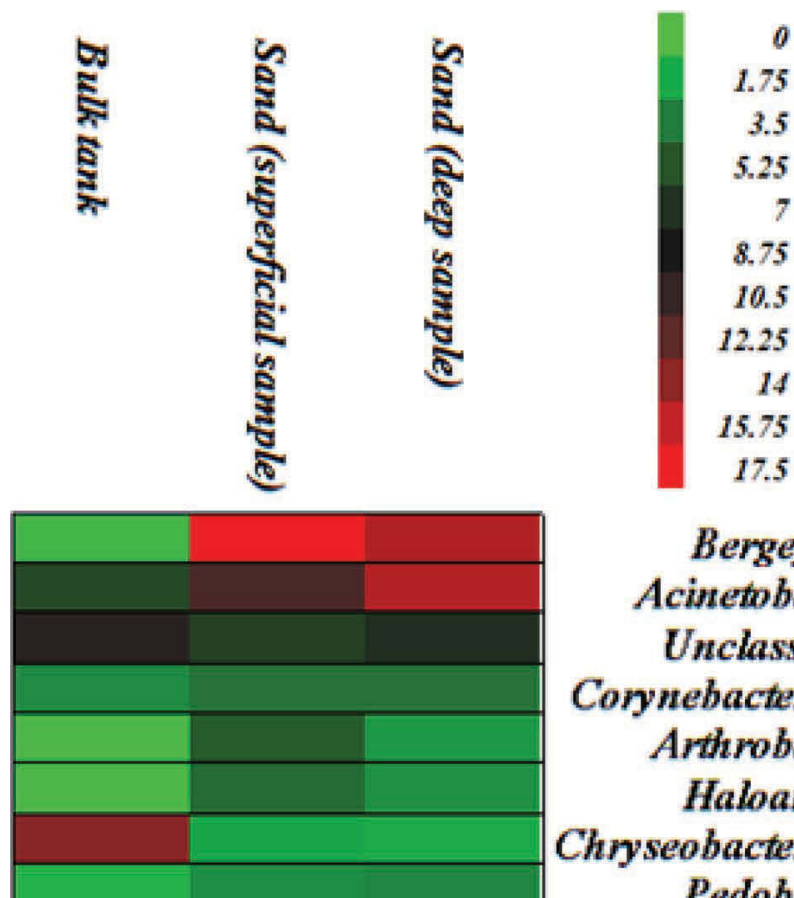

Bergeyella Acinetobacter

Unclassified

Corynebacterium

Arthrobacter

Haloanella

Chryseobacterium

Pedobacter

Sphingobacterium

Lysobacter

Flavobacterium

Calothrix

Janibacter

Cellvibrio

Pseudomonas

Thermomonas

Ruminococcus

Aerococcus

Lactobacillus

Bacteroides

Brachybacterium

Dietria

Hymenobacter

Paracoccus

Wautersiella

Serinicoccus

Luteimonas

Enhydrobacter

Blautia

Clostridium

Lactococcus

Figure 6. Mean relative abundance of the 30 most prevalent bacterial genera identified in the sand bedding and bulk tank milk samples. The scale represents the relative abundance of each bacterial genus. Color version available online. 
The Bergeyella and Acinetobacter genera were highly abundant in sand bedding samples. Whereas little is known about Bergeyella (Han et al., 2006), Acinetobacter is found in natural ecosystems and in the spoilage flora of foods (Kämpfer, 2014), and is a known opportunistic human pathogen (Touchon et al., 2014). The exact environmental reservoirs of Acinetobacter spp. are unknown (Touchon et al., 2014). The high abundance of Bergeyella, Acinetobacter, Chryseobacterium, and Enhydrobacter found in this study urges further research to determine their potential importance to the dairy industry.

\section{CONCLUSIONS}

Based on the results of microbiological and molecular biology analyses, we suggest that Lactococcus is a potential etiologic agent of mastitis in the outbreak studied. We identified L. lactis and L. garvieae in milk of affected cows, and the L. lactis isolates showed different RAPD patterns suggesting they originated from multiples reservoirs. The microbiome was assessed for several different samples. Lactococcus bacteria were highly abundant in most mastitic milk samples, but showed a low relative abundance in healthy milk samples. Furthermore, Lactococcus was detected in all environmental samples analyzed. We suggest that species within the Lactococcus genus are potential etiological agents of bovine mastitis. Further studies should be conducted to understand the pathogenic significance of the genus and L. lactis in particular in veterinary medicine and food safety.

\section{ACKNOWLEDGMENTS}

The authors thank Coordenação de Aperfeiçoamento de Pessoal de Nível Superior (CAPES, Brazil) for financial support, process number 99999.003177/201507. This project was partially supported by Agriculture and Food Research Initiative Competitive Grant no. 2013-67015-21233 from the USDA National Institute of Food and Agriculture (Washington, DC).

\section{REFERENCES}

Akopyanz, N., N. O. Bukanov, T. U. Westblom, S. Kresovich, and D. E. Berg. 1992. DNA diversity among clinical isolates of $\mathrm{He}$ licobacter pylori detected by PCR-based RAPD fingerprinting. Nucleic Acids Res. 20:5137-5142.

Bar, D., L. W. Tauer, G. Bennett, R. N. González, J. A. Hertl, Y. H. Schukken, H. F. Schulte, F. L. Welcome, and Y. T. Gröhn. 2008. The cost of generic clinical mastitis in dairy cows as estimated by using dynamic programming. J. Dairy Sci. 91:2205-2214.

Benson, D. A., I. Karsch-Mizrachi, D. J. Lipman, J. Ostell, and E. W. Sayers. 2009. GenBank. Nucleic Acids Res. 37:D26-D31.
Bouchard, D. S., B. Seridan, T. Saraoui, L. Rault, P. Germon, C. Gonzalez-Moreno, F. M. Nader-Macias, D. Baud, P. François, V. Chuat, F. Chain, P. Langella, J. Nicoli, Y. Le Loir, and S. Even. 2015. Lactic acid bacteria isolated from bovine mammary microbiota: Potential allies against bovine mastitis. PLoS ONE 10:e0144831.

Caporaso, J. G., J. Kuczynski, J. Stombaugh, K. Bittinger, F. D. Bushman, E. K. Costello, N. Fierer, A. G. Peña, J. K. Goodrich, J. I. Gordon, G. A. Huttley, S. T. Kelley, D. Knights, J. E. Koenig, R. E. Ley, C. A. Lozupone, D. McDonald, B. D. Muegge, M. Pirrung, J. Reeder, J. R. Sevinsky, P. J. Turnbaugh, W. A. Walters, J. Widmann, T. Yatsunenko, J. Zaneveld, and R. Knight. 2010. QIIME allows analysis of high-throughput community sequencing data. Nat. Methods 7:335-336.

Casalta, E., and M. C. Montel. 2008. Safety assessment of dairy microorganisms: The Lactococcus genus. Int. J. Food Microbiol. 126:271-273.

Cavanagh, D., G. F. Fitzgerald, and O. McAuliffe. 2015. From field to fermentation: The origins of Lactococcus lactis and its domestication to the dairy environment. Food Microbiol. 47:45-61.

Cole, J. R., Q. Wang, J. A. Fish, B. Chai, D. M. McGarrell, Y. Sun, C. T. Brown, A. Porras-Alfaro, C. R. Kuske, and J. M. Tiedje. 2014. Ribosomal Database Project: Data and tools for high throughput rRNA analysis. Nucleic Acids Res. 42:D633-D642.

Daly, M., E. Power, J. Björkroth, P. Sheehan, A. O'Connell, M. Colgan, H. Korkeala, and S. Fanning. 1999. Molecular analysis of Pseudomonas aeruginosa: Epidemiological investigation of mastitis outbreak in Irish dairy herds. Appl. Environ. Microbiol. 65:27232729 .

Davies, J., M. D. Burkitt, and A. Watson. 2009. Ascending cholangitis presenting with Lactococcus lactis cremoris bacteraemia: A case report. J. Med. Case Rep. 3:3.

Delbès, C., L. Ali-Mandjee, and M. C. Montel. 2007. Monitoring bacterial communities in raw milk and cheese by culture-dependent and -independent 16S rRNA gene-based analyses. Appl. Environ. Microbiol. 73:1882-1891.

Espeche, M. C., M. Pellegrino, I. Frola, A. Larriestra, C. Bogni, and M. E. F. Nader-Macías. 2012. Lactic acid bacteria from raw milk as potentially beneficial strains to prevent bovine mastitis. Anaerobe 18:103-109.

Fortin, M., S. Messier, J. Paré, and R. Higgins. 2003. Identification of catalase-negative, non-beta-hemolytic, gram-positive cocci isolated from milk samples. J. Clin. Microbiol. 41:106-109.

Furtado, D. N., S. D. Todorov, M. Landgraf, M. T. Destro, and B. D. Franco. 2014. Bacteriocinogenic Lactococcus lactis ssp. lactis DF04Mi isolated from goat milk: Characterization of the bacteriocin. Braz. J. Microbiol. 45:1541-1550.

Ganda, E. K., R. S. Bisinotto, D. H. Decter, and R. C. Bicalho. 2016. Evaluation of an on-farm culture system (Accumast) for fast identification of milk pathogens associated with clinical mastitis in dairy cows. PLoS ONE 11:e0155314.

Gröhn, Y. T., R. N. González, D. J. Wilson, J. A. Hertl, G. Bennett, H. Schulte, and Y. H. Schukken. 2005. Effect of pathogen-specific clinical mastitis on herd life in two New York State dairy herds. Prev. Vet. Med. 71:105-125.

Hadjisymeou, S., P. Loizou, and P. Kothari. 2013. Lactococcus lactis cremoris infection: Not rare anymore? BMJ Case Rep. http:// dx.doi.org/10.1136/bcr-2012-008479.

Han, Y. W., A. Ikegami, N. F. Bissada, M. Herbst, R. W. Redline, and G. G. Ashmead. 2006. Transmission of an uncultivated Bergeyella strain from the oral cavity to amniotic fluid in a case of preterm birth. J. Clin. Microbiol. 44:1475-1483.

Hertl, J. A., Y. T. Gröhn, J. D. G. Leach, D. Bar, G. J. Bennett, R. N. González, B. J. Rauch, F. L. Welcome, L. W. Tauer, and Y. H. Schukken. 2010. Effects of clinical mastitis caused by grampositive and gram-negative bacteria and other organisms on the probability of conception in New York State Holstein dairy cows. J. Dairy Sci. 93:1551-1560.

Inoue, M., A. Saito, H. Kon, H. Uchida, S. Koyama, S. Haryu, T. Sasaki, and M. Nishijima. 2014. Subdural empyema due to Lactococcus lactis cremoris: Case report. Neurol. Med. Chir. (Tokyo) $54: 341-347$. 
Kämpfer, P. 2014. Acinetobacter A2. Pages 11-17 in Encyclopedia of Food Microbiology (Second Edition). C. A. Batt and M. L. Tortorello, ed. Academic Press, Oxford, UK.

Kawamura, Y., N. Fujiwara, T. Naka, A. Mitani, H. Kubota, J. Tomida, Y. Morita, and J. Hitomi. 2012. Genus Enhydrobacter Staley et al. 1987 should be recognized as a member of the family Rhodospirillaceae within the class Alphaproteobacteria. Microbiol. Immunol. $56: 21-26$

Khoo, L. H., F. W. Austin, S. M. Quiniou, P. S. Gaunt, D. K. Riecke, A. M. Jacobs, K. O. Meals, A. W. Dunn, and M. J. Griffin. 2014. Lactococcosis in Silver Carp. J. Aquat. Anim. Health 26:1-8.

Klostermann, K., F. Crispie, J. Flynn, R. P. Ross, C. Hill, and W. Meaney. 2008. Intramammary infusion of a live culture of Lactococcus lactis for treatment of bovine mastitis: Comparison with antibiotic treatment in field trials. J. Dairy Res. 75:365-373.

Kuang, Y., K. Tani, A. J. Synnott, K. Ohshima, H. Higuchi, H. Nagahata, and Y. Tanji. 2009. Characterization of bacterial population of raw milk from bovine mastitis by culture-independent PCRDGGE method. Biochem. Eng. J. 45:76-81.

Larkin, M. A., G. Blackshields, N. P. Brown, R. Chenna, P. A. McGettigan, H. McWilliam, F. Valentin, I. M. Wallace, A. Wilm, R. Lopez, J. D. Thompson, T. J. Gibson, and D. G. Higgins. 2007. Clustal W and Clustal X version 2.0. Bioinformatics 23:2947-2948.

Lima, F. S., G. Oikonomou, S. F. Lima, M. L. Bicalho, E. K. Ganda, J. C. Filho, G. Lorenzo, P. Trojacanec, and R. C. Bicalho. 2015. Prepartum and postpartum rumen fluid microbiomes: Characterization and correlation with production traits in dairy cows. Appl. Environ. Microbiol. 81:1327-1337.

Mangin, I., E. Corroler, A. Reinhardt, and M. Gueguen. 1999. Genetic diversity among dairy lactococcal strains investigated by polymerase chain reaction with three arbitrary primers. J. Appl. Microbiol. 86:514-520.

Medrano-Galarza, C., J. Gibbons, S. Wagner, A. M. de Passillé, and J. Rushen. 2012. Behavioral changes in dairy cows with mastitis. J. Dairy Sci. 95:6994-7002.

Mofredj, A., H. Bahloul, and C. Chanut. 2007. Lactococcus lactis: An opportunistic bacterium? Med. Mal. Infect. 37:200-207. (in French)

Munoz, M. A., F. L. Welcome, Y. H. Schukken, and R. N. Zadocks. 2007. Molecular epidemiology of two Klebsiella pneumoniae mastitis outbreaks on a dairy farm in New York State. J. Clin. Microbiol. 45:3964-3971.

Munsch-Alatossava, P., J. P. Gauchi, B. Chamlagain, and T. Alatossava. 2012. Trends of antibiotic resistance in mesophilic and psychrotrophic bacterial populations during cold storage of raw milk. ISRN Microbiol. 2012:918208.

Navas, M. E., G. Hall, and D. El Bejjani. 2013. A case of endocarditis caused by Lactococcus garvieae and suggested methods for identification. J. Clin. Microbiol. 51:1990-1992.

NRC. 2001. Nutrient Requirements of Dairy Cattle. 7th rev. ed. Natl. Acad. Press, Washington, DC.

Oikonomou, G., M. L. Bicalho, E. Meira, R. E. Rossi, C. Foditsch, V. S. Machado, A. G. Teixeira, C. Santisteban, Y. H. Schukken, and R. C. Bicalho. 2014. Microbiota of cow's milk; distinguishing healthy, sub-clinically and clinically diseased quarters. PLoS ONE 9:e85904.

Oikonomou, G., V. S. Machado, C. Santisteban, Y. H. Schukken, and R. C. Bicalho. 2012. Microbial diversity of bovine mastitic milk as described by pyrosequencing of metagenomic 16s rDNA. PLoS ONE 7:e47671.

Oki, K., J. Dugersuren, S. Demberel, and K. Watanabe. 2014. Pyrosequencing analysis of the microbial diversity of airag, khoormog and tarag, traditional fermented dairy products of Mongolia. Biosci. Microbiota Food Health 33:53-64.
Plumed-Ferrer, C., A. Barberio, R. Franklin-Guild, B. Werner, P McDonough, J. Bennett, G. Gioia, N. Rota, F. Welcome, D. V Nydam, and P. Moroni. 2015a. Antimicrobial susceptibilities and random amplified polymorphic DNA-PCR fingerprint characterization of Lactococcus lactis ssp. lactis and Lactococcus garvieae isolated from bovine intramammary infections. J. Dairy Sci. 98:6216-6225.

Plumed-Ferrer, C., S. Gazzola, C. Fontana, D. Bassi, P. S. Cocconcelli, and A. von Wright. 2015b. Genome sequence of Lactococcus lactis ssp. cremoris Mast36, a strain isolated from bovine mastitis. Genome Announc. 3. http://dx.doi.org/10.1128/genomeA.00449-15.

Plumed-Ferrer, C., K. Uusikylä, J. Korhonen, and A. von Wright. 2013. Characterization of Lactococcus lactis isolates from bovine mastitis. Vet. Microbiol. 167:592-599.

Quigley, L., R. McCarthy, O. O'Sullivan, T. P. Beresford, G. F. Fitzgerald, R. P. Ross, C. Stanton, and P. D. Cotter. 2013. The microbial content of raw and pasteurized cow milk as determined by molecular approaches. J. Dairy Sci. 96:4928-4937.

Royster, E., and S. Wagner. 2015. Treatment of mastitis in cattle. Vet. Clin. North Am. Food Anim. Pract. 31:17-46.

Saitou, N., and M. Nei. 1987. The neighbor-joining method: A new method for reconstructing phylogenetic trees. Mol. Biol. Evol. $4: 406-425$

Sayers, E. W., T. Barrett, D. A. Benson, S. H. Bryant, K. Canese, V. Chetvernin, D. M. Church, M. DiCuccio, R. Edgar, S. Federhen, M. Feolo, L. Y. Geer, W. Helmberg, Y. Kapustin, D. Landsman, D. J. Lipman, T. L. Madden, D. R. Maglott, V. Miller, I. Mizrachi, J. Ostell, K. D. Pruitt, G. D. Schuler, E. Sequeira, S. T. Sherry, M. Shumway, K. Sirotkin, A. Souvorov, G. Starchenko, T. A. Tatusova, L. Wagner, E. Yaschenko, and J. Ye. 2009. Database resources of the National Center for Biotechnology Information. Nucleic Acids Res. 37:D5-D15.

Tailliez, P., J. Tremblay, S. D. Ehrlich, and A. Chopin. 1998. Molecular diversity and relationship within Lactococcus lactis, as revealed by randomly amplified polymorphic DNA (RAPD). System. Appl. Microbiol. 21:530-538.

Tamura, K., and M. Nei. 1993. Estimation of the number of nucleotide substitutions in the control region of mitochondrial DNA in humans and chimpanzees. Mol. Biol. Evol. 10:512-526.

Touchon, M., J. Cury, E. J. Yoon, L. Krizova, G. C. Cerqueira, C Murphy, M. Feldgarden, J. Wortman, D. Clermont, T. Lambert, C. Grillot-Courvalin, A. Nemec, P. Courvalin, and E. P. Rocha. 2014. The genomic diversification of the whole Acinetobacter genus: Origins, mechanisms, and consequences. Genome Biol. Evol. 6:2866-2882.

Weisburg, W. G., S. M. Barns, D. A. Pelletier, and D. J. Lane. 1991. $16 \mathrm{~S}$ ribosomal DNA amplification for phylogenetic study. J. Bacteriol. 173:697-703.

Werner, B., P. Moroni, G. Gioia, L. Lavín-Alconero, A. Yousaf, M. E. Charter, B. M. Carter, J. Bennett, D. V. Nydam, F. Welcome, and Y. H. Schukken. 2014. Short communication: Genotypic and phenotypic identification of environmental streptococci and association of Lactococcus lactis ssp. lactis with intramammary infections among different dairy farms. J. Dairy Sci. 97:6964-6969.

Wood, J., K. P. Scott, G. Avgustin, C. J. Newbold, and H. J. Flint. 1998. Estimation of the relative abundance of different Bacteroides and Prevotella ribotypes in gut samples by restriction enzyme profiling of PCR-amplified 16S rRNA gene sequences. Appl. Environ. Microbiol. 64:3683-3689.

Wyder, A. B., R. Boss, J. Naskova, T. Kaufmann, A. Steiner, and H. U. Graber. 2011. Streptococcus spp. and related bacteria: Their identification and their pathogenic potential for chronic mastitisA molecular approach. Res. Vet. Sci. 91:349-357. 